\title{
The fatigue characteristics of two-pin moment-resisting dowel furniture joints with different assembly time and glueline thickness
}

\begin{abstract}
The fatigue strength of two-pin dowel end to side-grain rubberwood furniture joints made from PVAc of different glueline thickness and joint assembly times were compared. Joints assembled immediately after machining had significantly higher strength compared to those joints assembled after 1 week and 1 month. The results showed that the allowable design stress for PVAc dowel adhesive joints of $0.01 \mathrm{~mm}$ glueline thickness could be set at $25 \%$ of its ultimate bending moment, which conforms to the strength requirements in service.
\end{abstract}

Keyword: Fatigue strength; PVAc; Joint strength; Adhesive joint; South East Asian Region 